\title{
Kinerja Reproduksi Induk Sapi Potong pada Usaha Peternakan Rakyat di Kecamatan Mojogedang
}

\author{
J. Riyanto ${ }^{*}$, Lutojo dan D. M. Barcelona \\ Program Studi Peternakan, Fakultas Pertanian, Universitas Sebelas Maret \\ Jl. Ir. Sutami 36 A Ketigan Surakarta \\ E-mail: jokoriyanto@staff.uns.ac.id
}

\begin{abstract}
ABSTRAK
Penelitian ini bertujuan untuk mengetahui kinerja reproduksi induk sapi potong terdiri dari sapi Simpo, sapi Limpo dan sapi PO yang dipelihara pada usaha peternakan rakyat. Penelitian dilakukan dengan metode survei pada peternak sapi potong induk sapi potong 60 ekor di Kecamatan Mojogedang Kabupaten Karanganyar Propinsi Jawa Tengah mulai Desember 2014 sampai Pebruari 2015. Parameter penelitian adalah post partum estrus (PPE), post partum mating (PPM), service per conception (S/C), days open (DO). Hasil penelitian dianalisis secara deskriptif. Kinerja reproduksi induk sapi Simpo, sapi Limpo dan sapi PO berturut-turut PPE: $3.56 \pm 0.73$ bulan, $3.93 \pm 0.40$ bulan, dan $6.75 \pm 4.68$, PPM: $3.85 \pm 0.70$ bulan, $3.79 \pm 0.51$ bulan, dan $4.42 \pm 1.23$, S/C: $1.45 \pm 0.20$ kali, $1.74 \pm 0.07$ kali, dan $1.38 \pm 0.38$ kali, DO: $5.33 \pm 0.58$ bulan, $8.44 \pm 4.65$ bulan, dan $9.27 \pm 5.93$ bulan, CI: $14.33 \pm 0.58$ bulan, $14.44 \pm 0.66$ bulan, dan $14.44 \pm 0.66$ bulan, Kesimpulan kinerja reproduksi induk sapi Simpo, sapi Limpo dan sapi PO di Kecamatan Mojogedang menunjukkan nilai post partum estrus (PPE) dan post partum mating (PPM) panjang dan service per conception (S/C) tinggi. Days open (DO) dan calving interval (CI) masih panjang.
\end{abstract}

Kata kunci: Kinerja reproduksi, induk sapi, sapi Simpo, sapi Limpo, sapi PO

\section{Reproductive Performance of The Beef Cattle Cow at The Farmers Livestock in The Mojogedang District}

\section{ABSTRACT}

This study aims to determine of the reproductive performance of beef cows consists are Simpo cow, Limpo cow and PO cow reared on the livestock. The research was conducted by survey on beef cattle 60 head in the District Mojogedang, Central Java Province from December 2014 through February 2015. The research parameter is post partum estrus (PPE), post partum mating (PPM), service per conception ( $S / C$ ), days open (DO). Results of the study were analyzed descriptively. Reproductive performance of Simpo cow, Limpo cow and PO cow are consecutive PPE: 3:56 0.73 months, $3.93 \pm 0: 40$ months, and $6.75 \pm 4.68$ months, PPM: $3.85 \pm 0.70$ months, $3.79 \pm 0.51$ months, and 4:42 \pm 1.23 months, $S / C: 1.45 \pm 0: 20$ times, $1.74 \pm 0: 07$ time, and 1:38 $\pm 0: 38$ times, DO: $5: 33 \pm$ $0: 58$ months, 8:44 \pm 4.65 months, and 9:27 \pm 5.93 months, CI: 14:33 $\pm 0: 58$ months, $14: 44 \pm 0.66$ months, and 14:44 \pm 0.66 months. The conclusion shows that the reproductive performance of the Simpo cow, Limpo cow and PO cow in District Mojogedang appears that the value of post-partum estrus (PPE) and post partum mating (PPM) is panjang.Service per conception $(S / C)$ is high. Days open (DO) and calving interval (CI) are both still long.

Keywords: Reproductive performance, beef cow, Simpo cow, Limpo cow and PO cow

\section{PENDAHULUAN}

Sapi merupakan penghasil daging utama di Indonesia. Persediaan dan permintaan daging di Indonesia terjadi kesenjangan. Kebutuhan atau permintaan akan daging jauh lebih besar daripada ketersediaan daging dalam negeri. Kebutuhan daging sapi pada tahun 2012 untuk konsumsi dan industri sebanyak 
484.000 ton sedangkan ketersediaannya sebesar 399.000 ton $(82,52 \%)$ dicukupi dari sapi lokal, sehingga terdapat kekurangan penyediaan sebesar 85.000 ton $(17,5 \%)$ (Direktorat Jenderal Peternakan, 2013). Kebutuhan daging dari dalam negeri yang masih kurang perlu dilakukan upaya peningkatan produksi daging diantaranya dengan melakukan peningkatan populasi dan produktivitas sapi potong.

Salah satu usaha untuk mengatasi masalah tersebut adalah perlu dilakukan usaha peningkatan kemampuan reproduksi ternak sapi. Penampilan reproduksi yang diamati antara lain melalui sistem perkawinan, umur pertama dikawinkan, umur penyapihan pedet, service per conception (S/C), umur pertama beranak, dan calving interval (CI) (Desinawati dan Isnaini, 2010), post partum estrus (PPE), post partum matting (PPM), dan days open (DO) (Leksanawati, 2010) serta lama kebuntingan (Bestari et al., 1999). Penampilan reproduksi dapat digunakan untuk menghitung waktu siklus perkembangbiakan ternak yang ada dapat digunakan untuk memperkirakan populasi ternak di masa yang akan datang.

Kabupaten Karanganyar merupakan salah satu daerah yang mulai dikembangkan ternak sapi potongnya di Jawa Tengah. Terdapat 17 Kecamatan di Kabupaten Karanganyar dimana Kecamatan Mojogedang merupakan salah satu Kecamatan yang memiliki populasi ternak sapi potong tertinggi daripada Kecamatan lainnya. Tahun 2013 populasi ternak sapi potong di Kecamatan Mojogedang yaitu 6.224 ekor (Badan Pusat Statistik Kabupaten Karanganyar, 2014). Akan tetapi penelitian mengenai kinerja reproduksi sapi potong di wilayah ini belum pernah dilakukan.

Berdasarkan permasalahan di atas maka dilaksanakan penelitian mengenai kinerja reproduksi sapi potong di Kecamatan Mojogedang, Kabupaten Karanganyar. Daya dukung yang dimiliki Kecamatan Mojogedang. Tujuan dari penelitian ini adalah untuk memperoleh informasi mengenai kinerja reproduksi sapi potong di
Kecamatan

Mojogedang

Kabupaten

Karanganyar.

\section{MATERI DAN METODE}

\section{Waktu dan Tempat Penelitian}

Penelitian dilaksanakan di Kecamatan Mojogedang, Kabupaten Karanganyar, Propinsi Jawa Tengah. Waktu penelitian dilaksanakan mulai Desember 2014 hingga Februari 2015.

\section{Materi dan Metode Penelitian}

Penelitian dilakukan dengan metode survei, yaitu dengan mengambil sampel dari suatu populasi dan menggunakan kuesioner sebagai alat pengumpul data (Singarimbun dan Effendi, 1989). Penelitian dibagi menjadi dua tahap yaitu tahap pra survei dan tahap survei. Tahap pra survei dilaksanakan untuk mengetahui lokasi pengambilan data dan menentukan responden. Tahap survei dilaksanakan untuk pengambilan data primer dan sekunder. Materi penelitian induk sapi potong bangsa sapi Simpo, sapi Limpo dan sapi PO pada usaha peternakan rakyat di Kecamatan Mojogedang. Induk sapi potong sudah beranak minimal satu kali.

\section{Jenis dan Sumber Data}

Data primer adalah data yang langsung dan segera diperoleh dari sumber data oleh peneliti (Surakhmad, 1998). Data primer diperoleh melalui kuesioner dan/atau wawancara kepada peternak responden. Data primer yang digunakan meliputi: identitas peternak, kepemilikan ternak, dan variabel penampilan reproduksi ternak.

Data sekunder adalah data yang secara tidak langsung memberikan informasi kepada pengumpul data, namun melalui dokumen atau pihak lain selain narasumber. Sumber data sekunder yang digunakan dalam penelitian ini adalah data dari Dinas Peternakan dan Perikanan Kabupaten Karanganyar, Badan Pusat Statistik (BPS) Kabupaten Karanganyar, petugas 
inseminator setempat dan penelitianpenelitian yang relevan. Data sekunder sebagai pelengkap antara lain keadaan peternakan sapi potong di lokasi, keadaan wilayah secara umum, recording peternakan.

\section{Parameter Penelitian}

Parameter yang diukur dalam penelitian ini meliputi: 1) Post Partum Estrus (PPE) diperoleh dengan menghitung jarak waktu antara induk beranak dengan estrus pertama setelah beranak (Wahyudi, 2014); 2) Satuan yang digunakan adalah bulan. Post partum matting (PPM) merupakan jarak waktu perkawinan pertama setelah beranak (Wahyudi, 2014). Satuan yang digunakan adalah bulan; 3) Service/conception (S/C) merupakan jumlah pelayanan inseminasi yang dibutuhkan oleh seekor betina sampai terjadi kebuntingan (Toelihere, 1981); 4) S/C merupakan suatu rasio keberhasilan perkawinan hingga bunting; 5) Days open (DO) adalah jarak waktu antara sapi beranak sampai dengan perkawinan yang menghasilkan kebuntingan (Wahyudi, 2014). Satuan yang digunakan adalah bulan; 6) Calving Interval dihitung dari catatan waktu beranak ke beranak berikutnya (Wahyudi, 2014). Satuan yang digunakan adalah bulan.

\section{Teknik Penentuan Lokasi dan Sampel Penelitian}

Kecamatan Mojogedang digunakan sebagai tempat penelitian karena daerah tersebut sangat potensial untuk pengembangan sapi potong di Kabupaten Karanganyar dengan populasi ternak 6224 ekor dan sesuai pengembangan Kabupaten Karanganyar dimana Kecamatan Mojogedang sebagai salah satu sentra penyediaan bakalan sapi potong.

Metode penentuan lokasi penelitian ditentukan secara purposive (sengaja) dengan pertimbangan waktu dan kemampuan serta jangkauan peneliti (Notohadiprawiro, 2006). Sampel sapi penelitian yaitu sapi potong yang sudah pernah beranak. Jumlah sampel yang diambil dalam penelitian ini dipilih 60 ekor sapi potong.

Pengambilan sampel bagi masingmasing desa menurut Mardikanto (2001) dilaksanakan secara proporsional dengan menggunakan rumus:

$$
\mathrm{Ni}=\frac{\mathrm{Nk}}{\mathrm{N}} \times 60
$$

Dimana: $\mathrm{N}_{\mathrm{i}}$ : Jumlah sampel yang diambil pada desa ke-i; $\mathrm{N}_{\mathrm{K}}$ : Ternak dari masingmasing desa; N: Ternak seluruhnya dari semua desa.

Sapi potong dalam penelitian ini berada di tiga desa yang dipilh yaitu Gebyok, Mojoroto, dan Mojogedang berturut-turut populasi sapi induk 327 ekor, 164 ekor, dan 147 ekor dari populasi sapi potong 793 ekor, 459 ekor, dan 342 ekor (Dinas Peternakan dan Perikanan Kabupaten Karanganyar, 2014)

\section{Teknik Pengumpulan Data}

Teknik wawancara untuk memperoleh data primer dengan melakukan wawancara langsung pada responden berdasarkan daftar pertanyaan atau kuesioner yang dibuat sebelumnya. Observasi ini dilakukan dengan pengamatan langsung pada objek yang diteliti sehingga didapatkan gambaran yang jelas mengenai objek tersebut. Studi Pustaka ini dilakukan dengan studi literatur pada buku maupun sumber yang relevan dan sesuai dengan penelitian.

\section{Metode Analisis Data}

Data primer ditabulasikan untuk dilakukan perhitungan berdasarkan parameter. Tahap selanjutnya adalah penghitungan rata-rata dan simpangan baku untuk penentuan kondisi umum obyek yang diamati. Penghitungan rata-rata dan simpangan baku menurut Dajan (1998) seperti yang disitasi Desinawati dan Isnaini (2010) adalah: 


$$
\begin{gathered}
\bar{x}=\frac{\sum x}{n} \\
S=\sqrt{\frac{\sum(x-\bar{x})^{2}}{n-1}}
\end{gathered}
$$

Dimana: $\bar{x}=$ rata-rata; $S=$ simpangan baku; $x=$ total sampel; $n=$ banyak sampel

Analisis yang digunakan adalah metode deskriptif dimana penelitian dimaksudkan untuk pengukuran yang cermat terhadap fenomena sosial tertentu dengan mengembangkan konsep dan menghimpun fakta yang ada di lapangan (Singarimbun dan Effendi, 1989).

\section{HASIL DAN PEMBAHASAN}

Kinerja reproduksi meliputi post partum estrus (PPE), post partum mating (PPM), service per conception (S/C), days open (DO), dan calving interval (CI) induk sapi Simpo, sapi Limpo dan sapi PO di Kecamatan Mojogedang Kabupaten Karanganyar dapat dilihat pada Tabel 1.

Rata-rata PPE sapi potong di Kecamatan Mojogedang yaitu $3.97 \pm 0.43$ bulan masih termasuk PPE yang tinggi. Menurut Toelihere (1981), interval antara partus ke estrus pertama pada sapi berkisar antara 50 sampai 60 hari atau 1,5-2 bulan. Waktu yang diperlukan untuk involusi uterus pada sapi berkisar antara 30 sampai 50 hari atau 1-1,5 bulan. Involusi uterus biasanya tercapai menjelang periode estrus pertama sesudah partus. Tingginya PPE diduga karena lamanya timbul estrus pasca melahirkan dan peternak yang teliti deteksi estrus induk sapi. Peternak tidak mendeteksi estrus secara spesifik hanya mengamati deteksi estrus melalui tingkah laku dan suara. Menurut Soeharsono et al (2010) estrus nyata ditandai spesifik dengan keadaan vulva dan vagina yang membengkak dan berwarna kemerahan serta sekresi cairan spesifik dari vagina. Nilai PPE sapi Limpo di Kecamatan Mojogedang yaitu $3.56 \pm 0.73$ bulan lebih pendek dibanding dengan nilai PPE sapi Limpo menurut Affandhy et al. (2006) yaitu $125,7 \pm 64,1$ hari atau $4,19 \pm 2,14$ bulan. Nilai PPE sapi Simpo yaitu $3.93 \pm 0.40$ bulan lebih panjang dibanding dengan nilai PPE sapi Limpo menurut Riatnawati (2010) dan Wahyudi (2014) yaitu $3,39 \pm 0,20$ bulan dan $3,72 \pm 2,14$ bulan. Nilai PPE sapi PO yaitu $4.42 \pm 1.23$ bulan lebih panjang dibanding dengan nilai PPE sapi PO menurut Riatnawati (2010) dan Wahyudi (2014) yaitu $4,14 \pm 0,39$ bulan dan $3,64 \pm 1,96$ bulan.

Rata-rata nilai PPM hasil penelitian yang telah dilakukan lebih pendek dibanding penelitian lain. Salisbury dan Vandemark (1985) mengatakan bahwa sapi betina seharusnya dikawinkan 60-80 hari atau 2-2,5 bulan setelah beranak karena diperlukan waktu minimal 50-60 hari atau 1,5-2 bulan untuk mencapai involusi uteri yang sempurna pada sapi. Hasil penelitian menunjukkan rata-rata PPM sapi potong di Kecamatan Mojogedang yaitu 4.02 \pm 0.35 . Hasil penelitian menunjukkan nilai PPM sapi Limpo di Kecamatan Mojogedang yaitu $3.85 \pm 0.70$ bulan tidak jauh berbeda dengan sapi menurut Riatnawati (2010) yaitu $3,43 \pm 0,20$ bulan dan lebih pendek dibanding dengan nilai PPM sapi Limpo menurut

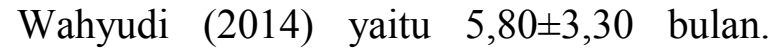
Nilai PPM sapi PO di Kecamatan Mojogedang yaitu $4.42 \pm 1.23$ bulan lebih pendek dibanding dengan nilai PPE sapi PO menurut Riatnawati (2010) dan Wahyudi (2014) yaitu $4,33 \pm 0,38$ bulan dan $6,85 \pm 4,10$ bulan. Nilai S/C sapi induk di Kecamatan Mojogedang tergolong normal karena menurut Toelihere (1977), S/C sapi induk berkisar 1,6 sampai 2,0. Penundaan PPM dapat meningkatkan S/C. Penundaan dimaksudkan untuk memperbaiki skor kondisi tubuh induk dan memberi kesempatan involusi uterus. Besar kecilnya nilai S/C dalam IB dipengaruhi ketidak telitian deteksi estrus oleh peternak dan ketidaktepatan waktu IB oleh inseminator (Nurkhafid, 2009), dan dan induk kekurangan nutrisi (Hardjopranjoto, 1995).

Hasil penelitian menunjukkan nilai S/C sapi Limpo di Kecamatan Mojogedang yaitu $1.45 \pm 0.20$ kali lebih kecil dibanding dengan nilai S/C sapi Limpo menurut Yulyanto et al 
Tabel 1. Kinerja reproduksi induk sapi potong (sapi Simpo, sapi Lipo dan sapi PO) di Kecamatan Mojogedang Kabupaten Karanganya

\begin{tabular}{lcccc}
\hline \multicolumn{1}{c}{ Parameter } & $\begin{array}{c}\text { Sapi } \\
\text { SimPO }\end{array}$ & $\begin{array}{c}\text { Sapi } \\
\text { LimPO }\end{array}$ & $\begin{array}{c}\text { Sapi } \\
\text { PO }\end{array}$ & $\begin{array}{c}\text { Rata-rata } \\
\text { (Kecamatan } \\
\text { Mojogedang) }\end{array}$ \\
\hline $\begin{array}{l}\text { Post partum estrus (PPE) } \\
\text { (bulan) }\end{array}$ & $3.56 \pm 0.73$ & $3.93 \pm 0.40$ & $4.42 \pm 1.23$ & $3.97 \pm 0.43$ \\
$\begin{array}{l}\text { Post partum mating (PPM) } \\
\text { (bulan) }\end{array}$ & $3.85 \pm 0.70$ & $3.79 \pm 0.51$ & $4.42 \pm 1.23$ & $4.02 \pm 0.35$ \\
$\begin{array}{l}\text { Service Per Conception (C/I) } \\
\text { (kali) }\end{array}$ & $1.45 \pm 0.20$ & $1.74 \pm 0.07$ & $1.38 \pm 0.38$ & $1.52 \pm 0.19$ \\
$\begin{array}{l}\text { Days open (DO) (bulan) } \\
\text { Calving interval (CI) (bulan) }\end{array}$ & $5.33 \pm 0.58$ & $5.40 \pm 0.73$ & $9.27 \pm 5.93$ & $6.67 \pm 2.25$ \\
& $14.33 \pm 0.58$ & $14.44 \pm 0.66$ & $14.89 \pm 1.17$ & $14.55 \pm 0.29$ \\
\hline
\end{tabular}

(2014) yaitu $1,52 \pm 0,39$ kali. Nilai S/C sapi Simpo di Kecamatan Mojogedang yaitu $1.74 \pm 0.07$ kali lebih kecil dibanding dengan nilai S/C sapi Simpo menurut Riatnawati (2010) dan Wahyudi (2014) yaitu 2,64 $\pm 0,29$

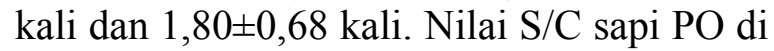
Kecamatan Mojogedang yaitu $1.38 \pm 0.38$ kali lebih kecil dibanding dengan nilai $\mathrm{S} / \mathrm{C}$ sapi PO menurut Riatnawati (2010) dan Wahyudi (2014) yaitu 2,28 $\pm 0,22$ kali dan $1,93 \pm 0,83$ kali.

Hasil penelitian menunjukkan nilai DO sapi Limpo di Kecamatan Mojogedang yaitu $5.33 \pm 0.58$ bulan lebih panjang dibanding dengan nilai DO menurut Yulyanto et al (2014) yaitu $172 \pm 19,21$ hari atau 5,73 $\pm 0,64$ bulan. Hasil penelitian menunjukkan nilai DO sapi Simpo di Kecamatan Mojogedang yaitu $5.40 \pm 0.73$ bulan lebih panjang dibanding dengan nilai DO menurut Illiyin (2006) yaitu $88,00 \pm 25,67$ hari atau $2,51 \pm 0,92$ bulan. Nilai DO sapi PO di Kecamatan Mojogedang yaitu $9.27 \pm 5.93$ bulan lebih panjang dibanding dengan Illiyin (2006) dan Wahyudi (2014) yaitu $107,73 \pm 29,48$ hari atau 3,59 $\pm 0,98$ bulan dan 7,44 $\pm 3,98$ bulan. Faktor fisiologis (missal PPE), manajerial (misal PPM) dan rasio $\mathrm{S} / \mathrm{C}$ dapat memperlama waktu DO. Bertambah lamanya waktu PPE dan PPM menyebabkan waktu DO lebih lama meskipun nilai rasio S/C sapi induk di Kecamatan Mojogedang lebih kecil dari sapi induk di wilayah lain. Selain itu, kematian embrio dapat mengakibatkan tertundanya estrus kembali akibat terbentuknya corpus luteum persisten (Hunter, 1981 cit. Illiyyin, 2006). Hal ini juga yang dapat menyebabkan waktu days open lebih lama meski nilai rasio $\mathrm{S} / \mathrm{C}$ rendah.

Hasil penelitian menunjukkan nilai CI sapi Limpo di Kecamatan Mojogedang yaitu $14.33 \pm 0.58$ bulan lebih pendek dibanding dengan nilai CI menurut Yulyanto et al (2014) yaitu $451,3 \pm 19,61$ hari atau $15,04 \pm 0,64$ bulan. Nilai CI sapi Simpo di Kecamatan Mojogedang yaitu $14.44 \pm 0.66$ bulan lebih pendek dibanding dengan nilai CI menurut Agustian (2008) dan Wahyudi (2014) yaitu $14,45 \pm 1,30$ bulan dan $15,67 \pm 3,30$ bulan. Nilai CI sapi PO di Kecamatan Mojogedang yaitu $14.89 \pm 1.17$ bulan lebih pendek dibanding dengan nilai CI menurut Agustian (2008) dan Wahyudi (2014) yaitu $14,95 \pm 1,99$ bulan dan $16,59 \pm 4,01$ bulan.

Waktu CI menggambarkan kemampuan induk sapi menghasilkan pedet dalam suatu ukuran waktu. Faktor yang memengaruhi jarak beranak adalah post partum estrus (PPE), post partum mating (PPM), dan S/C (Winarti dan Supriyadi, 2010). Semakin lama PPE dan PPM serta tingginya nilai $\mathrm{S} / \mathrm{C}$ maka jarak beranak akan semakin lama pula. Rata-rata nilai CI sapi potong di Kecamatan Mojogedang lebih baik dibanding dengan wilayah lain, namun menurut Hardjopranjoto (1995) efisiensi reproduksi pada sapi dianggap baik apabila jarak antar kelahiran tidak melebihi 12 bulan atau 365 hari. 


\section{KESIMPULAN}

Kinerja reproduksi sapi potong di Kecamatan Mojogedang menunjukkan nilai post partum estrus (PPE) dan post partum mating (PPM) masih lama dan service per conception (S/C) yang tinggi. Days open dan calving interval (CI) panjang.

\section{DAFTAR PUSTAKA}

Affandhy, L., P. Situmorang., W.C. Pratiwi., dan D. Pamungkas. 2006. Performans Reproduksi Sapi PO Induk Pada Pola Perkawinan Berbeda Dalam Usaha Peternakan Rakyat: Studi Kasus di Kabupaten Blora dan Pasuruan. Seminar Nasional Teknologi Peternakan dan Veteriner 2006. Sumber: http://peternakan.litbang. deptan.go.id, diakses: 7 Desember 2012.

Agustian, L. 2008. Kinerja Reproduksi Sapi Potong Perankan Ongole (PO) dan Sapi Silangan Simmental dengan Peranakan Ongole (SIMPO) di Daerah Kulon Progo. Skripsi. Fakultas Peternakan Universitas Gadjah Mada. Yogyakarta.

Badan Pusat Statistik. 2014. Karanganyar dalam Angka. Badan Pusat Statistik. Karanganyar.

Bestari, J., A. R. Siregar., P. Situmorang., Y. Sani., dan R. H. Matondang. 1999. Penampilan reproduksi sapi induk Peranakan Limousin, Charolais, Droughmaster, dan Hereford pada program IB di Kabupaten Agam Propinsi Sumatera Barat. dalam Seminar Nasional Peternakan dan Veteriner. Balai Penelitian Ternak. Bogor.

Desinawati, N., dan N. Isnaini. 2010. Penampilan reproduksi Sapi Peranakan Simmental di Kabupaten Tulungagung Jawa Timur. Jurnal Ternak Tropika Vol. 11: 41-47.

Direktorat Jenderal Peternakan. 2013. Produksi Daging Sapi Menurut
Provinsi. http://www. deptan.go.id. Diakses pada tanggal 28 September 2014.

Hardjopranjoto. 1995. Ilmu Kemajiran Ternak. Universitas Airlangga Press. Surabaya.

Illiyyin, R. H. F. 2006. Penampilan Induk Sapi Silangan Simmental Dengan Peranakan Ongole di Peternakan Rakyat di Daerah Istimewa Yogyakarta. Skripsi. Fakultas Peternakan Universitas Gadjah Mada. Yogyakarta.

Leksanawati, A. Y. 2010. Penampilan reproduksi induk sapi perah Peranakan Friesian Holstein di Kelompok Ternak KUD Mojosongo Boyolali. Skripsi Program Studi Peternakan Universitas Sebelas Maret. Surakarta.

Mardikanto. 2001. Dasar-Dasar Penyuluhan Pembangunan Pertanian. Universitas Sebelas Maret Press, Surakarta.

Notohadiprawiro, T. 2006. Pertanian Lahan Kering di Indonesia: Potensi, Prospek, Kendala dan Pengembangannya. Universitas Gadjah Mada Press, Yogyakarta.

Nurkhafid. 2009. Kinerja Reproduksi Sapi Induk Peranakan Ongole dan Silangan Simmental dengan Peranakan Ongole di Kecamatan Wates Kabupaten Kulon Progo. Skripsi. Fakultas Peternakan Universitas Gadjah Mada. Yogyakarta.

Riatnawati, T. 2010. Karakteristik dan Kinerja Induk Sapi Peranakan Ongole dan Sapi persilangan Simmental dengan Peranakan Ongole di Kecamatan Mlati Kabupaten Sleman. Skripsi. Fakultas Peternakan Universitas Gadjah Mada. Yogyakarta.

Singarimbun dan Effendi, 1995. Metode Penelitian Survai. LP3EI. Jakarta.

Soeharsono, Saptati dan Diwyanto. 2010. Kinerja reproduksi sapi potong lokal dan sapi persilangan hasil Inseminasi Buatan di Daerah Istimewa 
Yogyakarta. Seminar Nasional Teknologi Peternakan dan Veteriner 2010.

Surakhmad. 1998. Pengantar Penelitian Ilmiah: Dasar, Metode dan Teknik. Tarsito. Bandung.

Toelihere, M. R. 1981. Fisiologi Reproduksi pada Ternak. Angkasa. Bandung.

Toelihere, M. R. 1979. Inseminasi Buatan Pada Ternak. Angkasa. Bandung.

Wahyudi, R. P. 2014. Penampilan reproduksi sapi induk Peranakan Ongole dan silangan Simmental dengan Peranakan Ongole di Kecamatan Nguter Kabupaten Sukoharjo. Skripsi S1 Fakultas Peternakan Universitas Sebelas Maret Surakarta.

Winarti, E., dan Supriyadi. 2010. Penampilan reproduksi ternak sapi potong betina di Daerah Istimewa Yogyakarta. Seminar nasional Teknologi Peternakan dan Veteriner $2010 . \quad$ Sumber: http://peternakan.litbang.deptan.go.id , diakses 16 Desember 2014.

Yulyanto, C. A., Susilawati, T., dan Ihsan M. N. 2014. Penampilan reproduksi sapi Peranakan Ongole (PO) dan Sapi Peranakan Limousin di Kecamatan Sawoo Kabupaten Ponorogo dan Kecamatan Tugu Kabupaten Trenggalek. Fakultas Peternakan Universitas Brawijaya. Malang. 